\title{
Effects of Microwave Ablation on Papillary Thyroid Microcarcinoma: A Five-Year Follow-Up Report
}

\author{
Deng-Ke Teng, ${ }^{1, *}$ Wen-Hui Li, ${ }^{1, *}$ Jia-Rui Du, ${ }^{1}$ Hui Wang, ${ }^{1}$ Dong-Yan Yang, ${ }^{1}$ and Xiao-Li Wu ${ }^{2}$
}

Background: Some researchers have achieved favorable efficacy in the treatment of primary papillary thyroid microcarcinoma (PTMC) using microwave ablation (MWA). However, as PTMC is a slowly progressing disease, a long follow-up period is required to confirm treatment efficacy. Our study aim was to investigate the long-term efficacy and safety of ultrasound (US)-guided MWA in PTMC.

Methods: In this study, 41 patients with thyroid masses (41 nodules) were diagnosed with PTMC by fine-needle aspiration or core needle biopsy. They underwent US-guided MWA. Preablation ultrasonic images of the thyroid nodules were collected, and the volumes were measured. The patients had follow-up at 1, 3, 6, and 12 months in the first year and every 6 months from the second year on, after MWA. The volume reduction rates (VRRs) of the thyroid nodules were analyzed.

Results: In total, 40 of 41 nodules were completely ablated by MWA. After 60 months of follow-up, the volume significantly decreased from a median of $55.78 \mathrm{~mm}^{3}$ (quartile: $\left.21.50,112.20 \mathrm{~mm}^{3}\right)$ to $0 \mathrm{~mm}^{3}\left(0,0 \mathrm{~mm}^{3}\right.$ ) $(p<0.001)$, with a VRR of $99.37 \% \pm 4.02 \%$. Two patients developed hoarseness after ablation; one recovered within 10 minutes, and the hoarseness in the other patient resolved 2 months after the ablation. No recurrence, metastatic cervical lymph nodes, or distal metastasis was found during the follow-up period.

Conclusions: In this five-year follow-up, MWA presented favorable efficacy with satisfactory safety for the treatment of PTMC. It should be considered an alternative therapy to surgery and active surveillance for solitary PTMC.

Keywords: microwave ablation, thyroid cancer, treatment outcome, ultrasonography, follow-up studies

\section{Introduction}

T HE INCIDENCE OF papillary thyroid carcinoma has grown rapidly $(1,2)$, particularly with a drastic increase in the proportion of patients with papillary thyroid microcarcinoma (PTMC) (3), though the trauma of surgery is a significant drawback (4-6). Therefore, some experts recommend close active surveillance for solitary PTMC (7), but there are still a small number of patients who develop tumor progression and require surgical treatment $(8,9)$. Moreover, living with thyroid cancer may bring substantial psychological stress to some patients. Therefore, many researchers have called for a minimally invasive and effective way to treat PTMC.

Microwave ablation (MWA), a minimally invasive technology, has been accepted as an alternative therapy to conventional surgeries for liver and kidney cancers $(10,11)$. Some researchers have applied this technology in the treatment of benign thyroid nodules $(12,13)$, recurrent thyroid cancer, and metastatic cervical lymph nodes in recent years $(14,15)$. Some researchers have even achieved favorable efficacy in the treatment of primary PTMC using MWA (13,16-20), with the longest follow-up period reported being three years (21). However, PTMC is a slowly progressing disease, and requires a longer follow-up period to verify treatment efficacy.

In this study, we conducted a five-year follow-up analysis after ultrasound (US)-guided MWA of PTMC to evaluate the safety and efficacy of this technique.

\section{Materials and Methods}

\section{Study oversight}

The study protocol was approved by the ethics committee of our hospital. All subjects were diagnosed with PTMC by thyroid fine-needle aspiration (FNA) or core needle biopsy

\footnotetext{
${ }^{1}$ Department of Ultrasound, China-Japan Union Hospital of Jilin University, Changchun, China.

${ }^{2}$ Department of Ultrasound, The First Hospital of Jilin University, Changchun, China.

*These two authors contributed equally to this work.
} 
(CNB) and were clearly informed that MWA could not fully avert the risk of recurrence, lymphatic metastasis, or distal metastasis after treatment. Written informed consent was obtained from all study participants.

\section{Patients}

In this retrospective single-center study, 41 patients (13 males, 28 females) had pathologically diagnosed PTMC from June 2014 to October 2014 in our hospital and underwent US-guided MWA. Their ages ranged from 27 to 63 years, with an average age of $46.10 \pm 8.85$ years.

The study inclusion criteria were as follows: (i) a suspected thyroid nodule was confirmed as PTMC by FNA or CNB; (ii) a single nodule that was no more than $10 \mathrm{~mm}$ in greatest diameter; (iii) the thyroid nodule did not invade tissues surrounding the thyroid; (iv) no cervical lymph node metastasis was found by US, no distant metastasis was found by lung computed tomography (CT), and no distant metastasis was found by bone scan in patients with bone pain symptoms; and (v) patients who could not tolerate surgery or who refused both surgery and active surveillance after being fully informed.

The exclusion criteria were as follows: (i) other types of thyroid cancer; (ii) multiple thyroid nodules or the largest nodule was greater than $10 \mathrm{~mm}$ in diameter; (iii) nodules invaded tissues surrounding the thyroid; (iv) pregnant women; (v) dysfunction of the vocal cord on the opposite side; (vi) patients with coagulation disorders; (vii) patients who may not be able to tolerate MWA due to other serious illnesses; and (viii) patients who refused to undergo MWA.

\section{MWA system}

The MWA system (ECO-100A1) used in this study was produced by Nanjing ECO Co., Ltd. (Jiangsu, China). A cooled-tip needle for MWA was used for the treatment of the thyroid nodule; the needle was $1.6 \mathrm{~mm}$ in diameter, and the handle was $10 \mathrm{~cm}$ in length. The distance between the electrode and the needle tip was $3 \mathrm{~mm}$.

\section{US system}

A MyLab Twice US unit (Esaote, Italy) with an LA523 linear probe or Mindray Resona 7 US unit (Mindray, China) with an L14-5WU linear probe was used for recording images and guiding the MWA procedure.

\section{Preablation assessment}

Senior ultrasonographers who had over 20 years of experience with thyroid US collected the preablation ultrasonography data. All thyroid nodules were scanned from multiple angles across sections. Information on size, volume $(\mathrm{V}=\pi \mathrm{abc} / 6)$, calcification, blood flow distribution, location, and surrounding tissues was recorded to determine a practical approach and a proper strategy for MWA. All lesions were confirmed as PTMC by FNA or CNB.

\section{MWA procedure}

All US-guided procedures were performed by doctors who had more than five years of experience with MWA. The patients were placed in a supine position with their neck hyperextended. The skin was sterilized and draped. Thyroid MWA was performed under local anesthesia (1.0\% lidocaine) guided by US. Following Teng's needle puncture method, the skin was incised with a $16 \mathrm{G}$ short sharp needle $(21,22)$. With the guidance of real-time US imaging, a microwave antenna was inserted into the thyroid to ablate the PTMC lesions according to the predetermined strategy.

A combination of the fixed-needle technique and movingshot technique was adopted to ablate the lesions and surrounding tissues layer by layer, point to point. All ablation procedures were performed under the cross section. For lesions with a diameter of $\leq 5 \mathrm{~mm}$, we generally performed five insertions for ablation. The first three of the five punctures were located at the largest transverse section of the lesion. These three insertions were sequentially located on the area of the dorsal side of the lesion close to normal tissue, the center of the lesion, and the ventral area of the lesion near normal tissue. The fourth and fifth punctures were located at the "head" and "foot" regions of the lesion, respectively.

For lesions with a diameter of more than $5 \mathrm{~mm}, 8-10$ insertions were usually needed for ablation. The first four insertions were made on the largest cross section of the lesion. The first was made in the area near the normal tissue at the back of the lesion, and the second was made in the lower third of the lesion. The third was made in the upper third of the lesion, and the fourth was made in the region near the normal tissue on the ventral side of the lesion. Then two or three insertions were made in the head and foot regions of the lesion according to its size and shape. After ablating an area, we withdrew the antenna from the ablation area to the thyroid or the subcutaneous tissue and then adjusted the direction of antenna to insert it into the next position. The ablation process is shown in Figure 1.

The power output for each nodule was $20 \mathrm{~W}$. The ablation margin exceeded $2 \mathrm{~mm}$ from the edge of each nodule as much as possible. When near the carotid artery, trachea, esophagus, or recurrent laryngeal nerve, preablation hydrodissection by injection of normal saline was used to avoid heat injury to these structures. We used a $21 \mathrm{G}$ needle ( $38 \mathrm{~mm}$ in length) with a $20-\mathrm{mL}$ syringe (BD) as the puncture needle for puncture and injection of the isolation fluid. For lesions near the carotid vessels, we punctured and injected the fluid through the lateral neck. For lesions near the trachea, we punctured and injected the fluid through the isthmus. For lesions near the esophagus or recurrent laryngeal nerve, we used a combination of pathways from the lateral neck and isthmus to inject the isolation fluid.

The injection procedure consisted of two steps. First, the isolation fluid was injected into the tracheoesophageal groove through the isthmus. In most cases, satisfactory isolation could be obtained. If it was not, we injected the isolation fluid to the back of the thyroid gland through the lateral neck pathway so that the isolation fluid injected through the two pathways "joined" and a sufficient isolation effect could be achieved. Generally, the distance between the edge of the lesion and the dangerous zone was at least $5 \mathrm{~mm}$. Contrast-enhanced US was performed immediately after MWA to confirm whether the ablation area covered the predetermined ablation range. If so, the nodule was determined to be completely ablated, thyroid MWA was accomplished, and the ablation area was calculated and recorded. 
FIG. 1. Schematic diagram of the five antenna insertions performed during the ablation of a lesion less than $5 \mathrm{~mm}$ in diameter. An ablation strategy to ensure that the tumor is completely ablated and reduce the risk of recurrence. (a) The first three antenna insertions are performed to ablate the largest cross section of the lesion.

The antenna is inserted into the subcutaneous tissue. Then, the direction of the antenna is adjusted in the thyroid tissue or subcutaneous tissue to insert the antenna into the dorsal area of the lesion close to the normal tissue. The central and ventral areas of the lesion near the normal tissue are sequentially ablated. (b) After ablation of the largest section of the lesion is complete, we withdraw the antenna from the ablation area to the thyroid or the subcutaneous tissue and adjust the direction for the fourth insertion of the antenna into the "head" region near the edge of the lesion for ablation. (c) Finally, the fifth insertion is per-

formed by inserting the antenna into the "foot" region near the edge of the lesion for ablation.
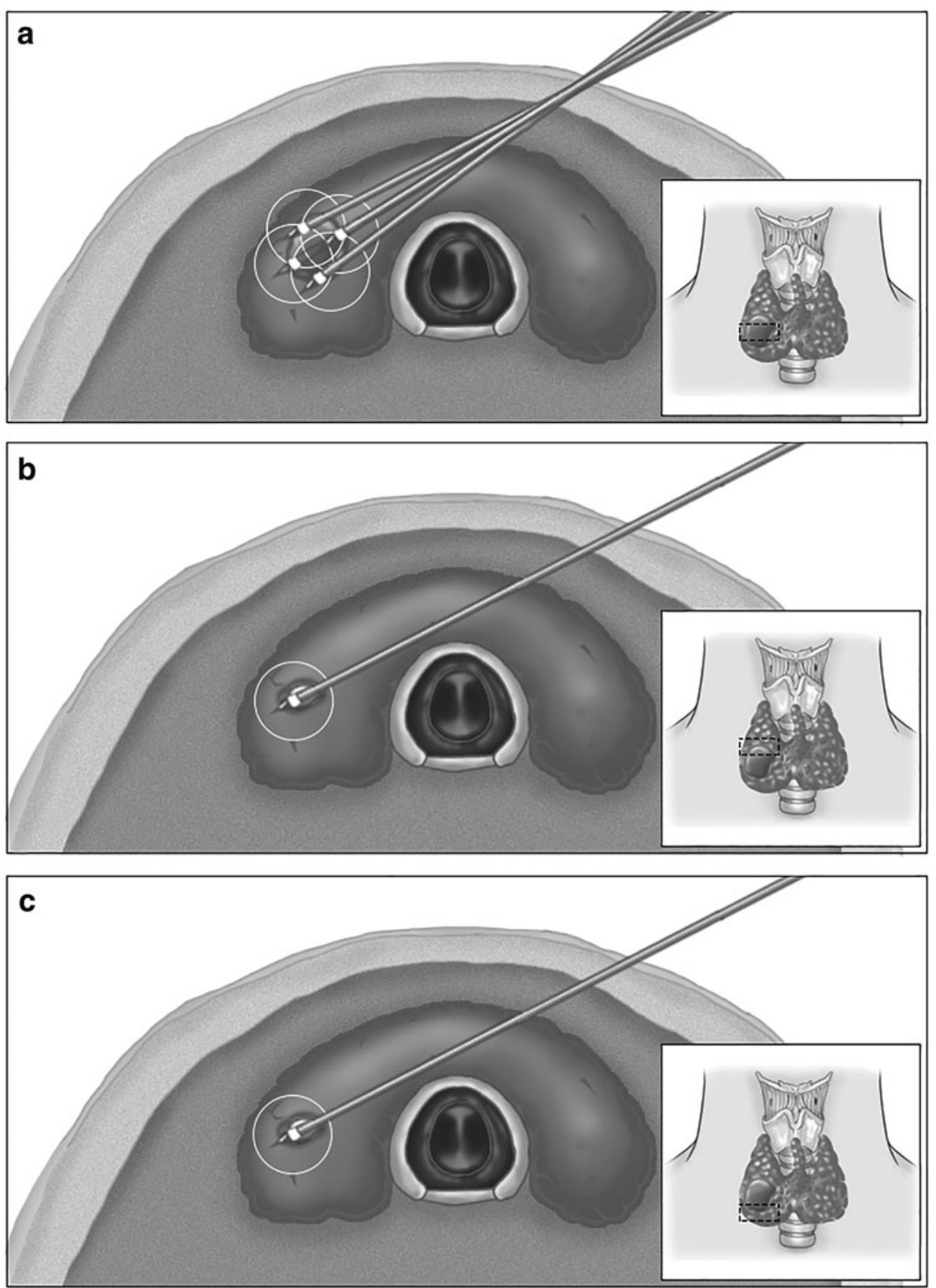

\section{Follow-up}

Before thyroid suppression therapy, thyroid function was re-examined at one month after MWA. Then, thyroid hormone suppression therapy was started, depending on the reexamination result to reduce the thyrotropin (TSH) level to below $0.1 \mathrm{mU} / \mathrm{L}$ (23). Thyroid US was carefully performed at $1,3,6$, and 12 months during the first year after MWA and every 6 months from the second year on to detect the recurrence of PTMC and metastatic cervical lymph nodes. The ablated range (both size and volume) and local blood flow distribution were recorded at every follow-up time point. The volume reduction ratio (VRR) was defined as VRR $(\%)=([$ primary volume - final volume $] \times 100 \%) /$ primary volume. However, as some cases presented a "black line" for the ablation area that healed, the volume could not be calculated. We defined this situation as completely ablated.

Tumor progression was defined according to the following two criteria: (i) new thyroid nodule confirmed by FNA or CNB to be PTMC; (ii) cervical or lateral lymph node metastasis confirmed by FNA, CNB, or thyroglobulin washout concentration. After ablation, patients routinely underwent lung CT every 12 months to detect recurrence and distal metastasis. However, for patients with symptoms or serious concerns regarding metastasis, ${ }^{18}$ F-fluorodeoxyglucose positron emission tomography CT or a bone scan was performed instead of lung CT.

\section{Statistical analysis}

Statistical analysis was performed with IBM SPSS Statistics for Windows v24.0 (IBM Corp., Armonk, NY). Data, 
including age and size, are presented as the mean \pm standard deviation. The volume is indicated by medians and quartiles. A pairwise comparison between the preablation volumes of nodules and postablation volumes of nodules at each followup time point was performed by applying the nonparametric Wilcoxon signed-rank test. A $p$-value of $<0.05$ was considered statistically significant.

\section{Results}

\section{Clinical characteristics}

Each of the 41 enrolled subjects with solitary PTMC presented with a single nodule that was confirmed to be PTMC by FNA or CNB. Their average age was $46.10 \pm 8.85$ years. Of the 41 thyroid nodules, 22 were located in the left lobe, and 19 were located in the right lobe. The largest diameter was $5.63 \pm 2.13 \mathrm{~mm}(2.80-10.00 \mathrm{~mm})$, and the two other dimension largest diameters were $4.64 \pm 1.72 \mathrm{~mm}$ (2.30$8.20 \mathrm{~mm})$ and $4.64 \pm 1.80 \mathrm{~mm}(1.50-8.40 \mathrm{~mm})$. The median volume was $55.78 \mathrm{~mm}^{3}\left(21.50,112.20 \mathrm{~mm}^{3}\right)$ (Table 1). The thyroid function of all participants was in the normal range before ablation and at one month after MWA. Beginning at one month after MWA, all patients received thyroid suppression treatment throughout the follow-up period.

\section{MWA procedure}

In the MWA procedure, the average working time was $179.51 \pm 86.54$ seconds (90.00-436.00 seconds), and the average ablation energy was $3590.24 \pm 1730.81 \mathrm{~J}$ (1800.00$8720.00 \mathrm{~J})$. Contrast-enhanced US revealed that the complete ablation rate of the nodules was $100 \%$.

\section{Complications}

Of the 41 enrolled subjects, no intolerable pain or obvious discomfort that required suspension of the treatment occurred during the ablation process. Two patients had hoarseness after ablation; one recovered within 10 minutes, which was considered transient hoarseness. One day after MWA, laryngoscopy showed normal bilateral vocal cord movement. The hoarseness in the other patient resolved two months after the ablation. Laryngoscopy performed on both the first day and three months after MWA revealed left vocal cord paralysis, which was considered recurrent laryngeal nerve injury during thyroid ablation. No skin burns, infection, or hypothyroidism occurred after ablation, and no analgesics were needed.

\section{Follow-up}

All subjects were followed up for more than 60 months after thyroid MWA. The median preablation volume of the nodule and postablation area at each follow-up time point are summarized in Table 1. The median preablation volume was $55.78 \mathrm{~mm}^{3}\left(21.50,112.20 \mathrm{~mm}^{3}\right)$. As the ablation margin was extended, the median area was $828.66 \mathrm{~mm}^{3}$ (554.22, $1433.20 \mathrm{~mm}^{3}$ ) at 1 month after ablation, which was significantly enlarged $(p<0.001)$. However, the volume significantly decreased at 12 months of follow-up $(p=0.019)$, with a median ablation area of $0.00 \mathrm{~mm}^{3}\left(0.00,36.76 \mathrm{~mm}^{3}\right)$. The volume was $0.00 \mathrm{~mm}^{3}\left(0.00,0.00 \mathrm{~mm}^{3}\right)$ and the VRR was $99.37 \% \pm 4.02 \%$ at 60 months of follow-up $(p<0.001)$. The ablation area volumes at each follow-up time point are shown in Figure 2.

Of the 41 ablated nodules, 40 were completely ablated with a complete regression rate of $97.56 \%$ (40/41). Two nodules were completely ablated at three months of followup. By the 36th month of follow-up, all lesions were completely ablated, except a lesion with large calcifications. This lesion was found to be completely ablated, except for the calcified area. The VRR of that lesion was $74.28 \%$. The size of the calcification did not change during the follow-up

Table 1. The Volume and Reduction Rate of the Nodules After Microwave Ablation

\begin{tabular}{|c|c|c|c|c|c|c|c|}
\hline \multirow[b]{3}{*}{ Time } & \multicolumn{4}{|c|}{ Volume of ablation area $\left(\mathrm{mm}^{3}\right)$} & \multicolumn{2}{|c|}{ Volume reduction rate (\%) } & \multirow{3}{*}{$\begin{array}{c}\mathrm{p}-\text { Value } \\
\text { (vs. volume } \\
\text { before } M W A\end{array}$} \\
\hline & \multirow{2}{*}{$\begin{array}{l}\text { Median } \\
\text { volume }\end{array}$} & \multirow[b]{2}{*}{ Range } & \multicolumn{2}{|c|}{ Percentiles } & \multirow{2}{*}{$\begin{array}{l}\text { Mean } \\
\text { reduction } \\
\text { rate }\end{array}$} & \multirow[b]{2}{*}{ Range } & \\
\hline & & & 25 & 75 & & & \\
\hline Before MWA & 55.78 & 7.4-338.2 & 21.50 & 112.20 & - & - & - \\
\hline $\begin{array}{l}\text { Immediately } \\
\text { after MWA }\end{array}$ & 1547.67 & $369.80-12543.70$ & 1047.40 & 2221.89 & - & - & $<0.001$ \\
\hline 1 month later & 828.66 & $130.10-10088.27$ & 554.11 & 1433.20 & $-2913.88 \pm 3193.74$ & -14178.95 to 53.89 & $<0.001^{\mathrm{a}}$ \\
\hline 3 months later & 403.86 & $0-2509.50$ & 189.25 & 679.12 & $-10.75 \pm 1244.26$ & -5794.02 to 100 & $<0.001$ \\
\hline 6 months later & 105.80 & $0-1290.16$ & 0.00 & 232.73 & $-297.19 \pm 583.75$ & -2360.33 to 583.75 & 0.101 \\
\hline 12 months later & 0.00 & $0-477.63$ & 0.00 & 36.76 & $-9.89 \pm 240.39$ & -896.14 to 240.39 & 0.019 \\
\hline 18 months later & 0.00 & $0-178.75$ & 0.00 & 0.00 & $89.64 \pm 38.68$ & -100.03 to 100.00 & $<0.001$ \\
\hline 24 months later & 0.00 & $0-51.43$ & 0.00 & 0.00 & $98.60 \pm 5.71$ & $72.94-100.00$ & $<0.001$ \\
\hline 30 months later & 0.00 & $0-49.19$ & 0.00 & 0.00 & $99.22 \pm 4.19$ & $73.68-100.00$ & $<0.001$ \\
\hline 36 months later & 0.00 & $0-48.07$ & 0.00 & 0.00 & $99.37 \pm 4.02$ & $74.28-100.00$ & $<0.001$ \\
\hline 42 months later & 0.00 & $0-48.07$ & 0.00 & 0.00 & $99.37 \pm 4.02$ & $74.28-100.00$ & $<0.001$ \\
\hline 48 months later & 0.00 & $0-48.07$ & 0.00 & 0.00 & $99.37 \pm 4.02$ & $74.28-100.00$ & $<0.001$ \\
\hline 54 months later & 0.00 & $0-48.07$ & 0.00 & 0.00 & $99.37 \pm 4.02$ & $74.28-100.00$ & $<0.001$ \\
\hline 60 months later & 0.00 & $0-48.07$ & 0.00 & 0.00 & $99.37 \pm 4.02$ & $74.28-100.00$ & $<0.001$ \\
\hline
\end{tabular}

${ }^{a}$ As the ablation margin was extended, the ablated area at one month after ablation was significantly larger than the preablation volume. MWA, microwave ablation. 


\section{Volume changes}

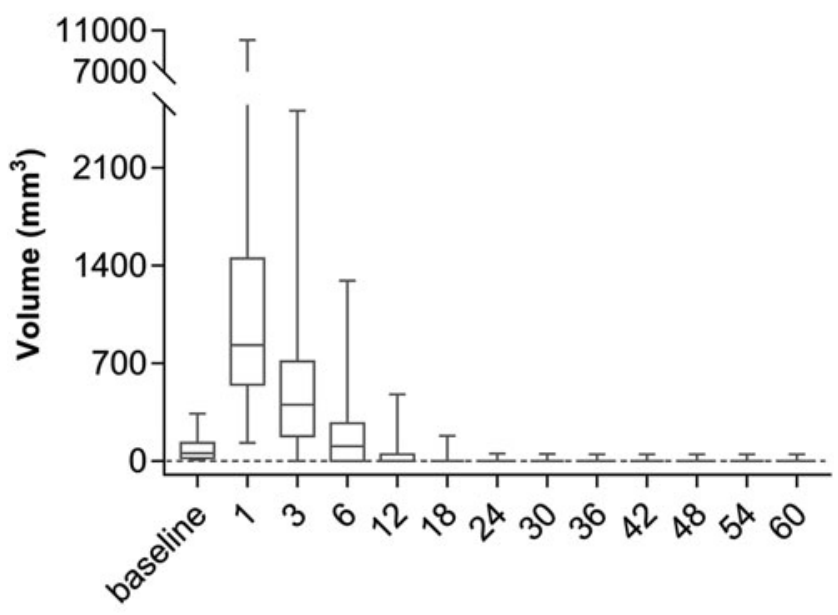

Follow-up time (month)

FIG. 2. The volume changes at each follow-up time point for the entire study cohort. The median volume for each follow-up time point is displayed as a bold line within each box.

period from 36 to 60 months. Therefore, the volume was found to be decreased at each follow-up time point before 36 months compared with the last time point, except for the first month after ablation (Fig. 2). After 36 months, there was no change in the volume (Table 1 ).

During the follow-up period, no recurrence or metastatic cervical lymph nodes were found by thyroid US. No distant metastasis was observed.

\section{Discussion}

This five-year follow-up study suggests that the safety and efficacy of US-guided MWA are promising for the treatment of solitary PTMC. Other studies using different interventional technologies, including radiofrequency ablation (RFA) and laser ablation (LA), have achieved favorable efficacy with satisfactory safety $(16,24,25)$. However, the longest follow-up period for MWA applied in PTMC was three years (21), which may not be enough time for such a slowly progressing tumor. Thus, we conducted a five-year follow-up to evaluate the efficacy of US-guided MWA in PTMC.

We found that the safety of MWA for the treatment of PTMC was satisfactory. First, all patients tolerated the process well. Because the type of disease we focused on was PTMC, which has a short ablation time due to its small volume compared with benign lesions, the patients enrolled in our study could withstand ablation under local anesthesia and did not require analgesics, which is consistent with other studies $(14,26)$. Second, complications occurred in only two patients. An experienced ultrasonographer and the utilization of hydrodissection can effectively protect nerves and organs and vessels surrounding the thyroid.

In this study, only one patient reported hoarseness for two months, caused by recurrent laryngeal nerve injury during MWA, which was confirmed by laryngoscopy. Another patient reported hoarseness for less than 10 minutes, and laryngoscopy after ablation showed normal bilateral vocal cord movement. Possible reasons for this transient hoarseness are as follows: the needle tip of the puncture needle may have punctured the recurrent laryngeal nerve during the injection of the isolation solution, and a small amount of lidocaine infiltrated around the recurrent laryngeal nerve during local anesthesia administration, causing transient recurrent laryngeal nerve paralysis.

The utilization of hydrodissection has brought about a low incidence rate of severe complications (27), which was only $2.4 \%$ in this follow-up study. In studies on ablation of PTMC, with the application of hydrodissection for protection during the ablation, the incidence of postablation complications using RFA, LA, and MWA was 3.5\% (31/875) (28), 2.8\% (2/ 46) (19), and4.3\% (1/36) (16), respectively, which is similar to our results.

Our study also demonstrates high efficacy of MWA for the treatment of PTMC over a five-year follow-up time. First, of the 41 solitary thyroid nodules, 40 of them, accounting for $97.56 \%$, were completely ablated. The remaining nodule with heavy calcification had a VRR of $74.28 \%$. The heavily calcified lesion was still present after thyroid MWA. Second, PTMC recurrence or metastasis did not occur during the fiveyear follow-up, which is consistent with systematic review results $(29,30)$. The high efficacy observed in our study can be attributed to the following reasons. First, a rigorous screening of patients was conducted. Only those with a single thyroid nodule and without lymph node metastasis on US were included. Moreover, the lymph node areas surrounding the thyroid were carefully detected, and suspected lymph nodes were examined using FNA, CNB, or thyroglobulin washout concentration for distinguishing lymphatic metastasis as much as possible.

Moreover, the ablation margin was extended. It exceeded more than $2 \mathrm{~mm}$ from the edge of each nodule to achieve complete ablation as much as possible, which may be a critical factor for averting recurrence of PTMC. As PTMC is a malignant tumor, appropriate extension of the ablation range in MWA can help reduce the risk of recurrence. For the treatment of primary hepatocellular carcinoma with MWA, the ablation area from the edge of the tumor is extended $\geq 5 \mathrm{~mm}$ (31). However, the thyroid is much smaller than the liver, and thus, it is difficult to achieve an extended area of $5 \mathrm{~mm}$ in PTMC. Therefore, we decided to extend the margin at least $2 \mathrm{~mm}$ from the edge of the lesion as a standard procedure for the treatment of PTMC with MWA, similar to Lim et al. (32). Immediate postablation contrast-enhanced US confirmed that the ablation range was expanded by more than $2 \mathrm{~mm}$. In fact, most lesions, especially those lesions $\leq 5 \mathrm{~mm}$ in diameter, often have an enlarged area that extends far beyond $2 \mathrm{~mm}$. However, during the ablation process, it is critical that the emitter electrode of the ablation antenna rather than the tip of the ablation antenna is placed at the edge of the lesion near the normal tissue. In this way, clinicians can ensure that the range of the ablated area extends beyond the lesion. Finally, TSH suppression therapy could be another significant factor for reducing recurrence.

There are some limitations to our study. First, as it is a single-center study with a small sample size, the efficacy of MWA for PTMC needs verification in a multicenter, large cohort prospective trial. Second, as PTMC is a slow progressive disease, a five-year follow-up period may still not be a long enough follow-up time. 
Third, the 2015 ATA guidelines (8) on the use of a TSH suppression strategy for low-risk thyroid carcinoma patients after surgery recommend maintaining TSH at $0.5-2 \mu \mathrm{m} / \mathrm{L}$. In this study, after referring to previously published literature on MWA for PTMC (23), the target value for TSH suppression treatment was set at below $0.1 \mu \mathrm{m} / \mathrm{L}$. This threshold may be too aggressive and could increase the risk of side effects. Therefore, prospective studies are needed in the future to determine what kind of TSH suppression strategy is appropriate for patients with PTMC after MWA. In addition, many lesions were diagnosed by FNA rather than CNB in this study. Without histological reports, some potentially relevant information could be missed.

In this five-year follow-up, MWA of solitary PTMC was effective and safe. It should be considered an alternative therapy to surgery and active surveillance for solitary PTMC.

\section{Author Disclosure Statement}

No competing financial interests exist.

\section{Funding Information}

This study was funded by the China Ultrasound Doctors Association (No. KJXX2019002), the Jilin Province Science and Technology Department (No. 20190303140SF), and the Finance Department of Jilin Province (No. SCZSY201701).

\section{References}

1. Kitahara CM, Sosa JA 2016 The changing incidence of thyroid cancer. Nat Rev Endocrinol 12:646-653.

2. Bray F, Ferlay J, Soerjomataram I, Siegel RL, Torre LA, Jemal A 2018 Global cancer statistics 2018: GLOBOCAN estimates of incidence and mortality worldwide for 36 cancers in 185 countries. CA Cancer J Clin 68:394-424.

3. Lim H, Devesa SS, Sosa JA, Check D, Kitahara CM 2017 Trends in thyroid cancer incidence and mortality in the United States, 1974-2013. JAMA 317:1338-1348.

4. Revelli L, Damiani G, Bianchi CB, Vanella S, Ricciardi W, Raffaelli M, Lombardi CP 2016 Complications in thyroid surgery. Harmonic scalpel, harmonic focus versus conventional hemostasis: a meta-analysis. Int J Surg 28(Suppl 1):S22-S32.

5. Chandrasekhar SS, Randolph GW, Seidman MD, Rosenfeld RM, Angelos P, Barkmeier-Kraemer J, Benninger MS, Blumin JH, Dennis G, Hanks J, Haymart MR, Kloos RT, Seals B, Schreibstein JM, Thomas MA, Waddington C, Warren B, Robertson PJ 2013 Clinical practice guideline: improving voice outcomes after thyroid surgery. Otolaryngol Head Neck Surg 148:S1-S37.

6. Jeannon JP, Orabi AA, Bruch GA, Abdalsalam HA, Simo R 2009 Diagnosis of recurrent laryngeal nerve palsy after thyroidectomy: a systematic review. Int J Clin Pract 63:624-629.

7. Xue S, Wang P, Hurst ZA, Chang YS, Chen G 2018 Active surveillance for papillary thyroid microcarcinoma: challenges and prospects. Front Endocrinol 9:736.

8. Haugen BR, Alexander EK, Bible KC, Doherty GM, Mandel SJ, Nikiforov YE, Pacini F, Randolph GW, Sawka AM, Schlumberger M, Schuff KG, Sherman SI, Sosa JA, Steward DL, Tuttle RM, Wartofsky L 20162015 American Thyroid Association Management Guidelines for adult patients with thyroid nodules and differentiated thyroid cancer: the American Thyroid Association Guidelines Task Force on Thyroid Nodules and Differentiated Thyroid Cancer. Thyroid 26:1-133.

9. Ito Y, Miyauchi A, Kihara M, Higashiyama T, Kobayashi K, Miya A 2014 Patient age is significantly related to the progression of papillary microcarcinoma of the thyroid under observation. Thyroid 24:27-34.

10. Filippiadis DK, Gkizas C, Chrysofos M, Siatelis A, Velonakis G, Alexopoulou E, Kelekis A, Brountzos E, Kelekis N 2018 Percutaneous microwave ablation of renal cell carcinoma using a high power microwave system: focus upon safety and efficacy. Int J Hyperthermia 34:10771081.

11. Izzo F, Granata V, Grassi R, Fusco R, Palaia R, Delrio P, Carrafiello G, Azoulay D, Petrillo A, Curley SA 2019 Radiofrequency ablation and microwave ablation in liver tumors: an update. Oncologist 24:e990-e1005.

12. Yan J, Qiu T, Lu J, Wu Y, Yang Y 2018 Microwave ablation induces a lower systemic stress response in patients than open surgery for treatment of benign thyroid nodules. Int J Hyperthermia 34:606-610.

13. Zhang L, Zhou W, Zhan W, Peng Y, Jiang S, Xu S 2018 Percutaneous laser ablation of unifocal papillary thyroid microcarcinoma: utility of conventional ultrasound and contrast-enhanced ultrasound in assessing local therapeutic response. World J Surg 42:2476-2484.

14. Yue WW, Chen L, Wang SR, Yu SJ 2015 Locoregional control of recurrent papillary thyroid carcinoma by ultrasound-guided percutaneous microwave ablation: a prospective study. Int J Hyperthermia 31:403-408.

15. Chang YW, Kim HS, Jung SP, Kim HY, Lee JB, Bae JW, Son GS 2016 Pre-ablation stimulated thyroglobulin is a better predictor of recurrence in pathological N1a papillary thyroid carcinoma than the lymph node ratio. Int $\mathbf{J}$ Clin Oncol 21:862-868.

16. Li J, Liu Y, Liu J, Qian L 2018 Ultrasound-guided percutaneous microwave ablation versus surgery for papillary thyroid microcarcinoma. Int J Hyperthermia 34:653-659.

17. Garberoglio R, Aliberti C, Appetecchia M, Attard M, Boccuzzi G, Boraso F, Borretta G, Caruso G, Deandrea M, Freddi M, Gallone G, Gandini G, Gasparri G, Gazzera C, Ghigo E, Grosso M, Limone P, Maccario M, Mansi L, Mormile A, Nasi PG, Orlandi F, Pacchioni D, Pacella CM, Palestini N, Papini E, Pelizzo MR, Piotto A, Rago T, Riganti F, Rosato L, Rossetto R, Scarmozzino A, Spiezia S, Testori O, Valcavi R, Veltri A, Vitti P, Zingrillo M 2015 Radiofrequency ablation for thyroid nodules: which indications? The first Italian opinion statement. J Ultrasound 18:423-430.

18. Teng D-K, Li H-Q, Sui G-Q, Lin Y-Q, Luo Q, Fu P, Du J-R, Jin C-X, Wang H 2019 Preliminary report of microwave ablation for the primary papillary thyroid microcarcinoma: a large-cohort of 185 patients feasibility study. Endocrine 64:109-117.

19. Zhou W, Ni X, Xu S, Zhang L, Chen Y, Zhan W 2019 Ultrasound-guided laser ablation versus surgery for solitary papillary thyroid microcarcinoma: a retrospective study. Int J Hyperthermia 36:897-904.

20. Li JM, Liu YJ, Liu JB, Qian LX 2018 Ultrasound-guided percutaneous microwave ablation versus surgery for papillary thyroid microcarcinoma. Int J Hyperthermia 34:653659.

21. Teng D, Sui G, Liu C, Wang Y, Xia Y, Wang H 2018 Long-term efficacy of ultrasound-guided low power mi- 
crowave ablation for the treatment of primary papillary thyroid microcarcinoma: a 3-year follow-up study. J Cancer Res Clin Oncol 144:771-779.

22. Teng D, Ding L, Wang Y, Liu C, Xia Y, Wang H 2018 Safety and efficiency of ultrasound-guided low power microwave ablation in the treatment of cervical metastatic lymph node from papillary thyroid carcinoma: a mean of 32 months follow-up study. Endocrine 62:648-654.

23. Yue W, Wang S, Yu S, Wang B 2014 Ultrasound-guided percutaneous microwave ablation of solitary T1N0M0 papillary thyroid microcarcinoma: initial experience. Int $\mathrm{J}$ Hyperthermia 30:150-157.

24. Ji LL, Wu Q, Gu J, Deng XD, Zhou W, Fan X, Zhou F 2019 Ultrasound-guided percutaneous laser ablation for papillary thyroid microcarcinoma: a retrospective analysis of 37 patients. Cancer Imaging 19:16.

25. Chung SR, Baek JH, Choi YJ, Lee JH 2019 Longer-term outcomes of radiofrequency ablation for locally recurrent papillary thyroid cancer. Eur Radiol 29:4897-4903.

26. Yue WW, Wang SR, Yu SJ, Wang B 2014 Ultrasoundguided percutaneous microwave ablation of solitary T1N0M0 papillary thyroid microcarcinoma: initial experience. Int J Hyperthermia 30:150-157.

27. Park HS, Baek JH, Park AW, Chung SR, Choi YJ, Lee JH 2017 Thyroid radiofrequency ablation: updates on innovative devices and techniques. Korean J Radiol 18:615623.

28. Kim C, Lee JH, Choi YJ, Kim WB, Sung TY, Baek JH 2017 Complications encountered in ultrasonographyguided radiofrequency ablation of benign thyroid nodules and recurrent thyroid cancers. Eur Radiol 27:3128-3137.

29. Cho SJ, Baek JH, Chung SR, Choi YJ, Lee JH 2019 Thermal ablation for small papillary thyroid cancer: a systematic review. Thyroid 29:1774-1783.

30. Chen J, Cao J, Qiu F, Huang P 2019 The efficacy and the safety of ultrasound-guided ablation therapy for treating papillary thyroid microcarcinoma. J Cancer 10:5272-5282.
31. Jiao D, Qian L, Zhang Y, Zhang F, Li C, Huang Z, Zhang L, Zhang W, Wu P, Han X, Duan G, Han J 2010 Microwave ablation treatment of liver cancer with $2,450-\mathrm{MHz}$ cooled-shaft antenna: an experimental and clinical study. J Cancer Res Clin Oncol 136:1507-1516.

32. Lim HK, Cho SJ, Baek JH, Lee KD, Son CW, Son JM, Baek SM 2019 US-guided radiofrequency ablation for lowrisk papillary thyroid microcarcinoma: efficacy and safety in a large population. Korean J Radiol 20:1653-1661.

Address correspondence to:

Hui Wang, MD

Department of Ultrasound

China-Japan Union Hospital of Jilin University No. 126, Xian Tai Street

Changchun 130000

China

E-mail: wanghui_tdk@163.com

Dong-Yan Yang, MD

Department of Ultrasound

China-Japan Union Hospital of Jilin University

No. 126, Xian Tai Street

Changchun 130000

China

E-mail: yangdongy@jlu.edu.cn

Xiao- $\mathrm{Li} W u, M D$

Department of Ultrasound

The First Hospital of Jilin University

Changchun 130000

China

E-mail:wx1721213@163.com 